\title{
Isolation of Sperm and Egg Cells from Pepper
}

\author{
Wei Deng \\ School of Life Sciences, Xiamen University, Xiamen 361102, People's Republic of China \\ Yunling Xie \\ School of Public Health, Sun Ya-sen University, Guangzhou 510080, People's Republic of China \\ Yilan Qiu ${ }^{1}$ \\ Hunan Province Key Laboratory of Crop Sterile Germplasm Resource Innovation and Application, \\ School of Life Science, Hunan Normal University, Changsha 410081, People's Republic of China
}

\begin{abstract}
Additional INDEX words. Capsicum annuum, in vivo-in vitro method, pollen tubes, egg apparatus, enzymatic digestion, mechanical dissection

Abstract. Pepper (Capsicum annuum) pollen is bicellular and contains a vegetative cell and a generative cell, which divides in pollen tubes to form two sperm cells. Sperm cells of pepper were isolated using an in vivo-in vitro method. Hand-pollinated styles were first grown in vivo for several hours, then cut from their base and cultured in vitro until pollen tubes grew from the cut end. When the pollen tubes were transferred to a breaking solution, sperm cells were released from broken tubes. Viable embryo sac cells of pepper were isolated using enzymatic digestion and mechanical dissection. Isolated ovules were digested using cellulase and pectinase for $\mathbf{4 0}$ minutes and then transferred to an enzyme-free solution for mechanical dissection. Three cells of the egg apparatus and a central cell were released from a cut at the chalazal end of each ovule by pressing on the micropylar area of the ovule with a microneedle. Optimal isolation conditions included $11 \%$ mannitol, $0.04 \% \mathrm{CaCl}_{2}, 1 \%$ bovine serum albumin (BSA), $1 \%$ cellulase, $1 \%$ pectinase, and $0.3 \%$ pectolyase. Using this protocol, populations of pepper egg cells, synergids, and central cells were isolated.
\end{abstract}

In vitro fertilization (IVF) is a process of fertilization where an egg is combined with sperm outside the body. The isolation and subsequent IVF of sperm and egg cells under controlled conditions provides a useful means to study higher plant fertilization in individual cells in the absence of other somatic tissue. In this way, the mechanisms controlling fertilization, male and female gamete recognition, and egg activation can be investigated. Isolated egg cells are not only used for IVF, but also provide an experimental basis to evaluate egg and zygote development (Wang et al., 2006). Kranz et al. (1991) conducted IVF of maize (Zea mays) using isolated sperm and egg cells, and finally generated fertile plants (Kranz and Lörz, 1993). However, a second IVF of higher plants was not reported until 14 years later, in rice [Oryza sativa (Uchiumi et al., 2007)]. This suggests that the establishment of IVF methods in higher plants is challenging, and studies have shown that the major obstacle is the isolation of sperm and egg cells.

The isolation of egg cells can serve as an experimental basis to perform egg cell developmental research at the molecular level. Dresselhaus et al. (1994) constructed a cDNA library from 128 maize egg cells using reverse transcription polymerase chain reaction and for the first time isolated genes expressed in egg cells. They subsequently compared the egg cDNA library with a library of 104 maize zygotes and isolated newly expressed zygote genes following IVF (Dresselhaus et al., 1996). Using a microarray screening technique, Lê et al. (2005)

Received for publication 14 May 2018. Accepted for publication 5 July 2018 This research was supported by grants from the National Nature Science Foundation of China (31301773), the Hunan Provincial Construct Program of the Key Discipline in Ecology (0713), Hunan Province Cooperative Innovation Centre of Engineering and New Products for Developmental Biology (20134486), and Hunan Provincial Key Laboratory of Crop Sterility Mechanism and Sterile Germplasm Resources Innovation (2016TP1011).

${ }^{1}$ Corresponding author. E-mail: qiu730822@163.com. compared and analyzed gene expression between 25 maize egg cells and 20 central cells in an attempt to identify differences in double fertilization of both cells. These molecular studies of eggs and zygotes required the use of isolated cells to avoid interference by genes from somatic tissues.

Pepper is an important horticultural crop grown throughout the world. Agronomically important traits have been introduced into the pepper by conventional breeding, but the application is currently limited by the lack of genetic resources or sexual incompatibility among different species. Nowadays, genetic transformation of the plant has become an important alternative for both basic and commercial plant breeding programs. However, pepper is considered to be a highly recalcitrant species with respect to in vitro regeneration and genetic transformation (Gammoudi et al., 2018). Isolated egg and sperm from different species can create distant hybridization between two species, which has a great potency during crop breeding. The isolation of egg and sperm cell of pepper has not previously been reported. In the present study, we describe a protocol for the successful isolation of mature living sperm, egg, synergid, and central cells from pepper. Our protocol provides a basis from which to perform IVF of pepper and molecular biological studies of the fertilization process, and opens up a great potency for pepper breeding to create excellent varieties.

\section{Materials and Methods}

The pepper cultivar 8214 , one of the important pepper parents used to cultivate many new pepper cultivars, is male fertile. '8214' pepper plantlets were grown in the Botany Garden at Xiamen University, Xiamen, People's Republic of China. They bloomed during March in the Xiamen area and had a flowering duration of $\approx 20 \mathrm{~d}$. 
Breaking pollen grains. Fresh mature pollen grains at anthesis were incubated in solutions containing 5\% to $20 \%$ mannitol $\left(270-1180 \mathrm{mOsmol} \cdot \mathrm{kg}^{-1} \mathrm{H}_{2} \mathrm{O}\right)$ or $5 \%$ to $20 \%$ sucrose (140-630 mOsmol. $\mathrm{kg}^{-1} \mathrm{H}_{2} \mathrm{O}$ ) for 5-10 $\mathrm{min}$. Following incubation, some pollen grains broke and released their cytoplasm content.

IN VITRO POLLEN TUBE INDUCTION. Mature pollen grains at anthesis were placed in a medium containing $0.1 \%(\mathrm{w} / \mathrm{v}) \mathrm{KH}_{2} \mathrm{PO}_{4}$, $0.05 \%$ (w/v) $\mathrm{CaCl}_{2}, 0.01 \%$ (w/v) $\mathrm{H}_{3} \mathrm{BO}_{3}, 0.01 \%$ (w/v) $\mathrm{KH}_{2} \mathrm{PO}_{4}$, and $10 \%$ to $20 \%$ sucrose at $\mathrm{pH} 6.5$ in room temperature $\left(25^{\circ} \mathrm{C}\right)$. Initial observations indicated that some pollen germinated and produced a short pollen tube. However, the tube tips were enlarged and rapidly broke. The medium was amended using 5\% to $20 \%$ polyethylene glycol (PEG 4500; Amresco, Solon, OH), which resulted in the generation of longer tubes that exhibited normal morphology.

IN VIVO-IN VITRO POLLEN TUBE INDUCTION. The style length of pepper is $\approx 0.6 \mathrm{~cm}$ and pollen tubes require $10 \mathrm{~h}$ to reach the ovary during March temperatures $\left(\approx 20 / 27{ }^{\circ} \mathrm{C}\right.$ night/day). The first step of our protocol involved emasculation of each flower at anthesis followed by hand-pollination of their stigma using fresh pollens. Pollen tubes were then grown in vivo for $9 \mathrm{~h}$. Following growth, styles were cut near the ovary and immersed in a medium containing $0.01 \%(\mathrm{w} / \mathrm{v}) \mathrm{H}_{3} \mathrm{BO}_{3}, 0.01 \%(\mathrm{w} / \mathrm{v})$ $\mathrm{KH}_{2} \mathrm{PO}_{4}, 0.01 \%(\mathrm{w} / \mathrm{v}) \mathrm{CaCl}_{2}$, and $20 \%(\mathrm{w} / \mathrm{v})$ sucrose at $\mathrm{pH} 6.0$ for 3-5 h until pollen tubes emerged from the cut end of the style. Styles with pollen tubes were transferred into a $6 \%$ to $8 \%$ mannitol solution (375-523 $\mathrm{mOsmol} \cdot \mathrm{kg}^{-1}$ $\mathrm{H}_{2} \mathrm{O}$ ). Pollen tubes that broke in solution released their contents, including two sperm cells.

Ovule Dissection. Pepper contains a polycarpous ovary with more than 100 anatropous ovules. These ovules were incubated in an enzyme solution containing $0 \%$ to $1.5 \%(\mathrm{w} / \mathrm{v})$ cellulase RS (Yakult Pharmaceutical Industry Co., Tokyo, Japan), 0\% to $1.5 \%(\mathrm{w} / \mathrm{v})$ pectinase (ServaFeinbiochemica, Munich, Germany), $0 \%$ to $0.5 \%(\mathrm{w} / \mathrm{v})$ pectolyase $\mathrm{Y} 23$ (Kikkoman Corp., Tokyo, Japan), $0.04 \%$ (w/v) $\mathrm{CaCl}_{2}, 1 \%$ (w/v) BSA, and $6 \%$ to $12 \%(\mathrm{w} / \mathrm{v})$ mannitol for 40-50 min with gentle shaking at 25 to $27{ }^{\circ} \mathrm{C}$. Ovules were then washed twice using an enzyme-free version of the aforementioned solution, and dissected under an inverted microscope. A microneedle was used to dissect the ovules. After cutting the chalazal end of the ovules and gently squeezing the micropyle end of each ovule with the microneedle, cells of the egg apparatus, and the central cell were released from the cut end of the ovule.

The isolated egg, synergid, and central cells were tested for viability using $0.5 \mathrm{mg} \cdot \mathrm{L}^{-1}$ fluorescein diacetate [FDA (Sigma-Aldrich, St. Louis, MO)] for $1 \mathrm{~min}$ and observed using a light microscope (DMR; Leica Microsystems, Wetzlar, Germany), with $495 \mathrm{~nm}$ wavelength according to HeslopHarrison and Heslop-Harrison (1970). The isolated sperms, eggs, synergids, and central cells were collected using a micromanipulator.

The osmolality of all solutions was measured using an osmometer (OSMOMAT 030; Gonotec, Berlin, Germany).

\section{Results}

ISOLATION OF GENERATIVE CELLS. Dehiscence of six pepper anthers occurred at anthesis (Fig. 1A). Pollen grains placed into a solution containing $9 \%$ mannitol for $\approx 5$ min ruptured and released cytoplasm contents, including ellipse-shaped generative cells (Fig. 1B). Most pollen grains ruptured in a 5\% mannitol solution, and generative cells quickly converted to a rounded shape, which also ruptured. Relative to the $5 \%$ mannitol solution $\left(270 \mathrm{mOsmol} \cdot \mathrm{kg}^{-1} \mathrm{H}_{2} \mathrm{O}\right)$, a decreased number of broken pollen grains were observed in the $9 \%$ mannitol solution $\left(510 \mathrm{mOsmol} \cdot \mathrm{kg}^{-1} \mathrm{H}_{2} \mathrm{O}\right)$; however, the released generative cells retained their ellipse shape for $\approx 10 \mathrm{~min}$ (Fig. 1C). In $20 \%$ mannitol solution (1180 mOsmol $\cdot \mathrm{kg}^{-1} \mathrm{H}_{2} \mathrm{O}$ ), pollen grains seldom ruptured. The released generative cells in the $9 \%$ mannitol solution were collected using a micromanipulator and presented as Fig. 1D.
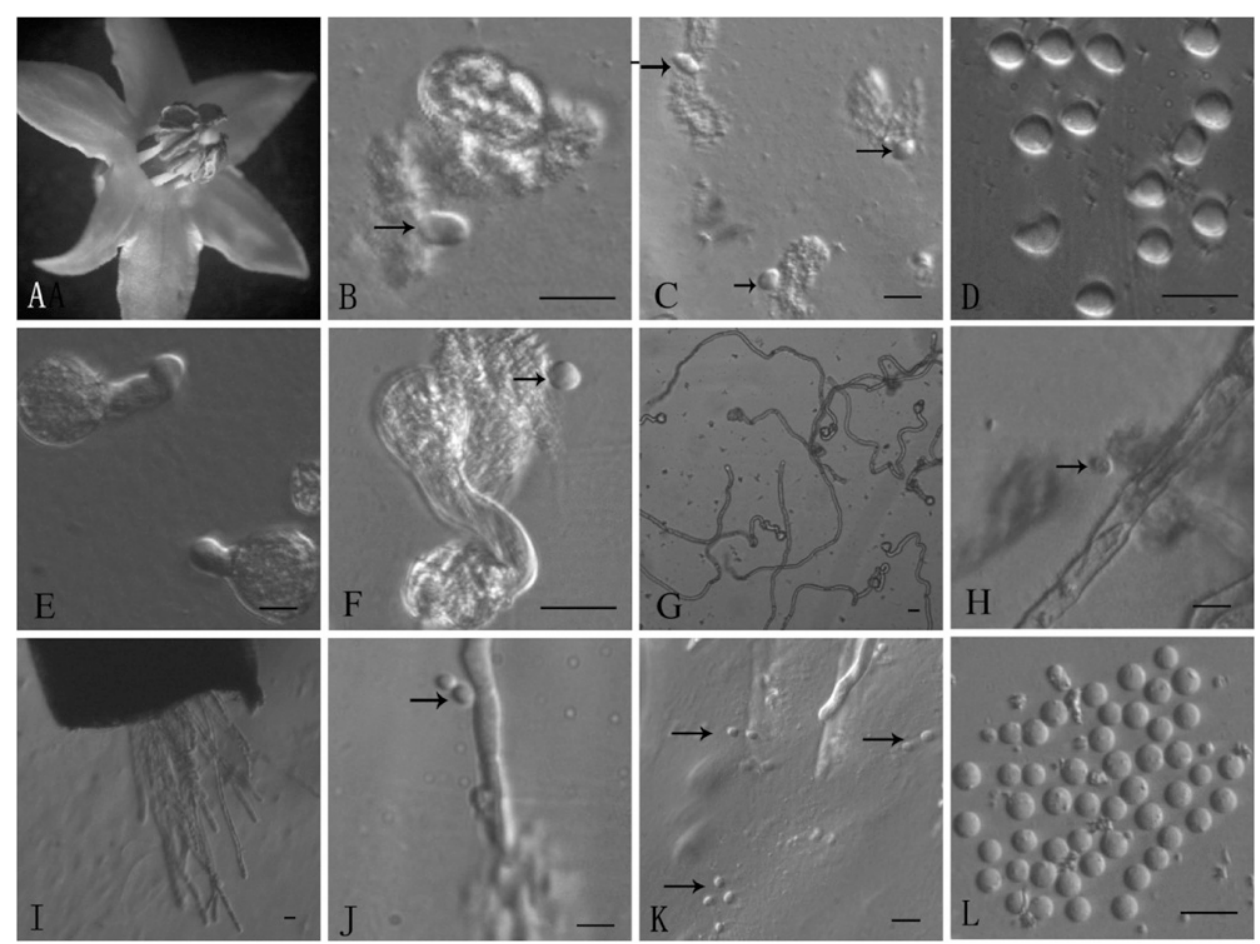

Fig. 1. Isolation of generative cells and sperm cells in pepper: (A) pepper flower at anthesis with dehiscent anthers; (B) release of generative cell (arrow) from a broken pollen grain; (C) release of cytoplasm and generative cells (arrows) from pollen grains; (D) the population of generative cells collected using a micromanipulator; (E) germinated of in vitro pollen grains and formation of short pollen tubes in sucrose medium; $(\mathbf{F})$ breakage of in vitro pollen tube and release of a generative cell (arrow); (G) in vitro pollen tubes win a medium containing sucrose and polyethylene glycol; (H) breakage of in vitro pollen tube and release of a generative cell (arrow); (I) growth of in vivo-in vitro pollen tubes from the cut end of a style after $9 \mathrm{~h}$ growth in vivo and $3 \mathrm{~h}$ growth in vitro; (J) breakage of pollen tube and release of two sperm cells (arrow); (K) breakage of pollen tubes and release of many pairs of sperm cells (arrows); and (L) the population of sperm cells collected using a micromanipulator (bar $=10 \mu \mathrm{m})$. 
Two sperm cells form in a single developing pollen tube. Therefore, pollen tube formation was initiated before sperm cell isolation. On incubation of mature pollen grains in a medium containing $0.05 \%(\mathrm{w} / \mathrm{v})$ $\mathrm{CaCl}_{2}, 0.01 \%$ (w/v) $\mathrm{H}_{3} \mathrm{BO}_{3}, 0.1 \%$ (w/v) $\mathrm{KH}_{2} \mathrm{PO}_{4}$, and $20 \%(\mathrm{w} / \mathrm{v})$ sucrose $\left(760 \mathrm{mOsmol} \cdot \mathrm{kg}^{-1} \quad \mathrm{H}_{2} \mathrm{O}\right.$, $\mathrm{pH} 5.6$ ), more than $30 \%$ of grains germinated and produced short pollen tubes (Fig. 1E). In medium containing sucrose as an osmotic regulator; however, pollen tubes grew more slowly, and growth discontinued after $30 \mathrm{~min}$ of culture, and many of the pollen tubes ruptured to release the content with ellipse-shaped generative cells (Fig. 1F).

Pollen grain germination was also effective using PEG as an osmotic regulator to replace sucrose. In medium containing 15\% PEG, pollen grain germination exceeded $30 \%$ and the average tube length (of 100 tubes) was $116.45 \mu \mathrm{m}$. Using this growth medium, pollen tube growth ceased after $1 \mathrm{~h}$ of culture. In $10 \%$ PEG and $15 \%$ sucrose mediums, however, pollen germination frequency sharply increased, and average tube length (of 20 tubes) was $722.45 \mu \mathrm{m}$ following $1 \mathrm{~h}$ of culture (Fig. 1G). In vitro pollen tubes were transported into a solution containing $9 \%$ mannitol to rupture the tubes and release their contents. However, in many cases, in vitro pollen tubes released only one "generative" cell (Fig. $1 \mathrm{H})$. This observation indicated that in vitro, many generative cells within pollen tubes did not divide to form two sperm cells.

ISOLATION OF SPERM CELLS. Flowers were hand-pollinated at anthesis and grown in vivo for $9 \mathrm{~h}$. Each style was excised, and the cut ends immersed in media containing $0.05 \%(\mathrm{w} / \mathrm{v}) \mathrm{CaCl}_{2}$, $0.01 \%(\mathrm{w} / \mathrm{v}) \mathrm{H}_{3} \mathrm{BO}_{3}, 0.01 \%(\mathrm{w} / \mathrm{v}) \mathrm{KH}_{2} \mathrm{PO}_{4}$, and $15 \%(\mathrm{w} / \mathrm{v})$ sucrose, with an osmolality of $570 \mathrm{mOsmol} \cdot \mathrm{kg}^{-1} \mathrm{H}_{2} \mathrm{O}$, at $\mathrm{pH}$ 5.5. Following $3 \mathrm{~h}$ of incubation, pollen tubes grew from the cut end of the style (Fig. 1I), at which stage the style with pollen tubes was transferred to a bursting solution containing $9 \%(\mathrm{w} / \mathrm{v})$ mannitol. Pollen tubes then ruptured in solution and their contents, including two sperm cells and a vegetative nucleus, were released (Fig. 1J). The newly released sperm cells from pollen tubes were generally elongated but quickly became round (Fig. 1K). Two sperm cells per pollen tube were collected using a micromanipulator and presented as Fig. 1L.

ISOLATION OF EMBRYO SAC CELLS. Ovules of pepper (Fig. 2A) were collected at anthesis and subjected to enzyme treatment (Fig. 2B). Following $40 \mathrm{~min}$ of incubation in enzymatic solution,

ovules were washed twice in enzyme-free isolation solution. The nucellus was then excised from treated ovules using a microneedle. The embryo sac outline was apparent in the nucellus (Fig. $2 \mathrm{C}$ ), which indicated the exact position for sac dissection. The chalazal end of the nucellus was carefully cut, and the nucellar micropylar end was squeezed with a microneedle to release the egg cell and two synergid cells (Fig. 2D). From each nucellus, three egg apparatus cells were released, which then clumped together. The released egg apparatus cells were easily distinguishable as egg cells or synergid cells in solution by their cell structure and morphology. Egg cells were larger than synergid cells; however synergid cells contained more cytoplasm. Also, synergid cell nuclei were located to one side and displayed the same polarity, which differed to that of the egg cell (Fig. 2E). All three egg apparatus cells displayed FDA fluorescence, suggesting they remained viable following the isolation procedures (Fig. $2 \mathrm{~F})$. Occasionally, one of the two isolated synergid cells did not 
display FDA fluorescence despite remaining intact (Fig. 2G), suggesting degeneration of that cell (Fig. 2H). Viable egg cells exhibiting FDA fluorescence were separated from synergid cells (Fig. 2I and J) and collected individually using a micromanipulator (Fig. 2K). Synergid cells were also collected individually (Fig. 2L). Newly isolated egg cells showed strong FDA fluorescence within $1 \mathrm{~h}$, which continued until $3 \mathrm{~h}$ after isolation.

When ovules were cut at the correct position and damage to the central cell was avoided, release of central cells was achieved by pushing the micropylar end of the nucellus (Fig. $2 \mathrm{M})$. At anthesis, central cells were easy to release from the dissected nucellus. However, it was difficult to isolate central cells from flowers at $15 \mathrm{~h}$ after anthesis. Newly isolated central cells also displayed strong FDA fluorescence (Fig. 2N), indicating viability. Central cells (Fig. 2O) were collected into a group using a micromanipulator (Fig. 2P).

SELECTION OF OPTIMAL ISOLATION CONDITIONS. More than 100 ovules are produced within each pepper ovary. Typically, $\approx 40$ 60 ovules can be dissected within $1 \mathrm{~h}$. Dissection of ovules was conducted in an enzyme digestion solution. To avoid continued enzyme digestion that could reduce or eliminate egg viability, the ovules were incubated in the enzymatic solution for only 40 min. The enzymatic solution was then removed and ovules were dissected in an enzyme-free solution. The components and concentrations of enzymes in the digesting solution were effective in isolating the cells of embryo sac. Among the enzymes, pectolyase was necessary to digest ovule epidermis. Ovules could not be effectively dissected using other enzymes in the absence of pectolyase. The optimal concentration of pectolyase was $0.3 \%$. Lower concentrations of pectolyase (e.g., $0.1 \%$ ) made peeling of the integument difficult. Higher concentrations (e.g., $0.5 \%$ ) allowed ovules to be more easily isolated; however, the embryo sac cells adhered together making it difficult to separate egg cells from synergid cells. Pectinase also played a role in digestion of nucellar cells.
Without pectinase, embryo sac cells became tightly conglutinated and starch stuck to the surface of the cells. This increased the difficulty in separating egg cells resulting in lower numbers being isolated. The role of cellulase in digestion was mainly to digest the cell wall of egg apparatus cells and to release the embryo sac cells as protoplasts with a clean surface. This further enhanced the ability to separate egg cells from synergids. Optimal enzymatic concentrations for digestion were $1 \%$ cellulase, $1 \%$ pectinase, and $0.03 \%$ pectolyase (Table 1 ).

The osmolality of enzymatic digesting and dissecting solutions affected egg cell isolation and their continued viability. All three egg cells could be isolated at $8 \%$ mannitol osmolality; however, the cells became increasingly inflated and the cytoplasm density was reduced. FDA fluorescence testing showed that these egg cells lost viability only $30 \mathrm{~min}$ after isolation. Increasing the mannitol concentration to $11 \%$ gave optimal conditions, provided a larger number of isolated egg cells (seven egg cells per 50 ovules in $1 \mathrm{~h}$ ) that remained viable for up to $120 \mathrm{~min}$ (Table 2).

\section{Discussion}

To date, IVF of higher plants has only been achieved in maize (Kranz and Lörz, 1993) and rice (Uchiumi et al., 2007), two monocotyledons. The fertilization features of maize and rice are not representative of all plants; however, there is a need for further investigation into IVF of other types, particularly dicotyledonous species. In our study, viable sperm and egg cells from pepper (a dicotyledon) were successfully isolated. Our results demonstrate that an adequate number of sperm and egg cells can be isolated, allowing for transcriptomics research into fertilization of pepper. This provides entry into a new field of the research into the sexual reproduction of dicotyledonous pepper.

SPERM CELl ISOLATION FROM PEPPER. Sperm cell isolation is required for performing IVF and investigating microgametogenesis.

Table 1. Effect of enzymes on isolation of egg cells in pepper.

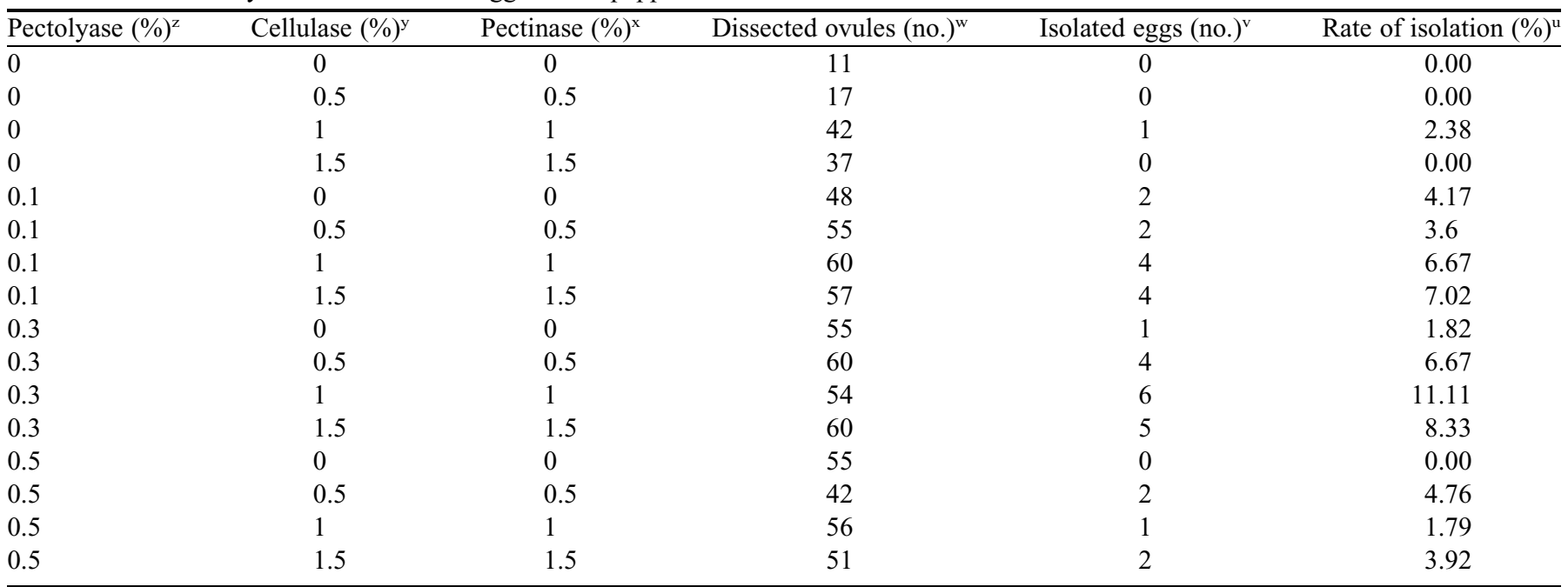

${ }^{\mathrm{z}}$ Concentration of pectolyase in the digesting solution.

${ }^{\mathrm{y}}$ Concentration of cellulose in the digesting solution.

${ }^{\mathrm{x}}$ Concentration of pectinase in the digesting solution.

${ }^{\mathrm{w}}$ Ovules were firstly digested in the digesting solution with enzyme, and then dissected in the dissection solution without enzymes.

${ }^{v}$ After digestion and dissection in $1 \mathrm{~h}$, the ovules released the eggs.

${ }^{u}$ Percent isolated eggs per 100 dissected ovules in $1 \mathrm{~h}$. 
Table 2. Effect of different osmotic pressure on the isolation of egg cell in pepper.

\begin{tabular}{lcccr}
\hline Mannitol concn $(\%)^{\mathrm{z}}$ & Dissected ovules (no. $)^{\mathrm{y}}$ & ${\text { Isolated eggs (no. })^{\mathrm{x}}}^{-}$ & Rate of isolation (\%) $^{\mathrm{w}}$ & Duration of fluorescence (min) $^{\mathrm{v}}$ \\
\hline $8\left(523 \mathrm{mOsmol} \cdot \mathrm{kg}^{-1} \mathrm{H}_{2} \mathrm{O}\right)$ & 50 & 3 & 6.00 & 30 \\
$10\left(638 \mathrm{mOsmol} \cdot \mathrm{kg}^{-1} \mathrm{H}_{2} \mathrm{O}\right)$ & 50 & 4 & 8.00 & 60 \\
$11\left(680 \mathrm{mOsmol} \cdot \mathrm{kg}^{-1} \mathrm{H}_{2} \mathrm{O}\right)$ & 50 & 7 & 12.00 & 120 \\
$12\left(724 \mathrm{mOsmol} \cdot \mathrm{kg}^{-1} \mathrm{H}_{2} \mathrm{O}\right)$ & 50 & 5 & 10.00 & 60
\end{tabular}

${ }^{\mathrm{z}}$ Mannitol in the digesting and dissecting solution determines the osmotic pressure of solution, which affected the condition of the cells.

${ }^{\mathrm{y}}$ Ovules were digested in the digesting solution with $1 \%$ pectinase, $1 \%$ cellulose, and $0.03 \%$ pectolyse, and then dissected in the dissection solution without enzymes.

${ }^{\mathrm{x}}$ After digestion and dissection in $1 \mathrm{~h}$, ovules released the eggs.

${ }^{\text {w}}$ Percent isolated eggs per 100 dissected ovules in $1 \mathrm{~h}$.

${ }^{\mathrm{v}}$ Duration of fluorescein diacetate fluorescence in the viable eggs.

Two types of pollen are characteristic of angiosperms at anthesis: bicellular and tricellular pollen. Sperm isolation is relatively straightforward in tricellular pollen species. Generally, when tricellular pollen grains are incubated in a medium under osmotic pressure, the grains readily break and release their contents, including two sperm cells. The isolation of sperm cells in bicellular pollen species is more difficult because of the division of each generative cell resulting in the formation of two sperm cells in the pollen tube (Wang et al., 2006). Consequently, to isolate the sperm cells, it is first necessary to induce pollen tube growth. In other bicellular pollen species, the generative cell did not divide to form two sperm cells within in vitro pollen tubes unless certain amino acids were added (Read et al., 1993), indicating a defective in vitro pollen tube.

The mature pollen grain of pepper is bicellular and comprised a vegetative cell and a generative cell. Generative cell and sperm cell isolation in pepper has not previously been reported. Although previous studies have demonstrated the release of pollen content from in vitro pollen tubes in mannitol mediums, only generative cells have been released. To achieve sperm isolation, we applied an in vivo-in vitro technique (Shivanna et al., 1988) to culture the entire pollinated styles that had been grown for $9 \mathrm{~h}$ in vivo. The whole style was then excised and inserted into a medium for in vitro culture. After pollen tubes emerged from the sectioned end of the style following $3 \mathrm{~h}$ of in vitro growth, the styles with pollen tubes were transferred to a breaking solution. Two sperm cells were released from the broken tubes. At this point, a 'population' of sperm cells can be collected with a micromanipulator. This method for sperm isolation provides an opportunity to conduct IVF of pepper and to identify unique genes and proteins that may be specifically involved in microgametogenesis in pepper and other species.

EGG CELL ISOLATION FROM PEPPER. The isolation of egg cells from higher plants is necessary before carrying out IVF and is fundamental in the studies of egg and zygote developmental mechanism using molecular biological methods. However, the egg cells are deeply embedded in ovules, which are located within ovaries, and egg isolation is generally considered more complex than sperm isolation. There are two principal factors that determine successful egg cell isolation: the technical ability to dissect ovules under an inverted microscope and the egg isolation conditions. Optimal egg isolation conditions depend on the enzyme concentration and osmotic pressure in the enzyme-containing and isolation solutions. It is generally difficult to dissect ovules without enzymatic digestion and can even be difficult to dissect after digestion. We found that following digestion in solution containing suitable enzymes, ovules became soft and were relatively easy to dissect. In our study, pectolyase in enzymatic digestion appeared to contribute to the softening of ovules, allowing for easier dissection. Celluloses and pectinase in solution remove the cell wall of egg apparatus cells, which enabled easier extrusion of the egg apparatus cells from ovule cut end. High concentrations of enzymes negatively affected egg cell isolation because three cells of egg apparatus were generally released and often tightly bound, making isolation of egg cells more difficult. Low enzyme concentrations were not effective for egg cell isolation. The optimal enzymatic solution for the isolation of egg cells from pepper contained $1 \%(\mathrm{w} / \mathrm{v})$ cellulase, $1 \%(\mathrm{w} / \mathrm{v})$ pectinase, $0.3 \%(\mathrm{w} / \mathrm{v})$ pectolyase, and six egg cells were isolated from 54 ovules in $1 \mathrm{~h}$ (Table 1). Under these conditions, isolated egg cells displayed FDA fluorescence more strongly and for a longer time, suggesting improved cell viability following isolation. The osmotic pressure of embryo sac cells is higher than nucellar somatic cells, and different species have varying osmotic pressures (Imre and Kristóf, 1999; van Went and Kwee, 1990). In our study, when the pressure of enzymatic and isolating solutions was low, egg apparatus cells were difficult to release and cells were more easily broken during dissection. In higher pressure solutions, the released egg apparatus cells shrank and their FDA fluorescence was short, indicating reduced cell viability (Table 2). The importance of osmotic materials in enzyme-containing digestion solutions and isolation solutions needs to be considered, both in terms of frequency of egg cells released and their length of viability. In our study, an $11 \%$ mannitol solution was found to be optimal for isolating maximum numbers of egg cells from pepper while also achieving lengthy cell viability.

\section{Literature Cited}

Dresselhaus, T., C. Hagel, H. Lörz, and E. Kranz. 1996. Isolation of a full-length cDNA encoding calreticulin from a PCR library of in vitro zygotes of maize. Plant Mol. Biol. 31:23-34.

Dresselhaus, T., H. Lörz, and E. Kranz. 1994. Representative cDNA libraries from few plant cells. Plant J. 5:605-610.

Gammoudi, N., T.S. Pedro, A. Ferchichi, and C. Gisbert. 2018. Improvement of regeneration in pepper: A recalcitrant species. In Vitro Cell. Dev. Biol. Plant 54:145-153.

Heslop-Harrison, J. and Y. Heslop-Harrison. 1970. Evaluation of pollen viability by enzymatically-induced fluorescence; intracellular hydrolysis of fluorescein diacetate. Stain Technol. 45:115-120.

Imre, K. and Z. Kristóf. 1999. Isolation and osmotic relations of developing megagametophytes of Torenia fournieri. Sex. Plant Reprod. 12:152-157.

Kranz, E., J. Bautor, and H. Lörz. 1991. In vitro fertilization of single, isolated gametes of maize mediated by electrofusion. Sex. Plant Reprod. 4:12-16. 
Kranz, E. and H. Lörz. 1993. In vitro fertilization with isolated, single gametes results in zygotic embryogenesis and fertile maize plants. Plant Cell 5:739-746.

Lê, Q., J.F. Gutièrrez-Marcos, L.M. Costa, S. Meyer, H.G. Dickinson, H. Lörz, E. Kranz, and S. Scholten. 2005. Construction and screening of subtracted cDNA libraries from limited populations of plant cells: A comparative analysis of gene expression between maize egg cells and central cells. Plant J. 44:167-178.

Read, S.M., A.E. Clarke, and A. Bacic. 1993. Requirement for division of generative nucleus in cultured pollen tubes of Nicotiana. Protoplasma 174:101-115.
Shivanna, K.R., H. Xu, P. Taylor, and R.B. Knox. 1988. Isolation of sperms from the pollen tubes of flowering plants during fertilization. Plant Physiol. 87:647-650.

Uchiumi, T., I. Uemura, and T. Okamoto. 2007. Establishment of an in vitro fertilisation system in rice (Oryza sativa L.). Planta 226:581589.

van Went, J.L. and H.S. Kwee. 1990. Enzymatic isolation of living embryo sacs of Petunia. Sex. Plant Reprod. 3:257-262.

Wang, Y.Y., A. Kuang, S.D. Russell, and H.Q. Tian. 2006. In vitro fertilisation as a tool for investigating sexual reproduction of angiosperms. Sex. Plant Reprod. 19:103-115. 